Referencia para citar este artículo: Ravelo-Medina, M., \& Radovic-Sendra, Y. (2018). Representaciones de lo político en estudiantes secundarios en Santiago de Chile: resignificando el sentido de la formación ciudadana. Revista Latinoamericana de Ciencias Sociales, Niñez y Juventud, 16(1), 389-402. doi:10.11600/1692715x.16124

\title{
Representaciones de lo político en estudiantes secundarios en Santiago de Chile: resignificando el sentido de la formación ciudadana*
}

\author{
MARCIA RAVELO-MEDINA** \\ Profesora Universidad de Chile, Chile. \\ YUBITZA RADOVIC-SENDRA *** \\ Profesora Universidad de Chile, Chile.
}

\section{Artículo recibido en octubre 14 de 2016; artículo aceptado en diciembre 15 de 2016 (Eds.)}

- Resumen (descriptivo): en este artículo presentamos los resultados - desde el discurso del estudiantado-de la investigación "Representaciones de lo político en estudiantes y profesores en la educación secundaria de la Región Metropolitana. Criterios para una nueva propuesta de formación ciudadana", realizada en Santiago de Chile. La investigación tuvo una fase exploratoria cuantitativa que recogió en estudiantes y docentes su percepción sobre la política, así como algunos conceptos asociados, tales como democracia, poder, participación. Le siguió una etapa cualitativa en la que indagamos los significados del valor y el sentido de la política y la democracia, a nivel escolar y social. Los resultados muestran un distanciamiento de la política institucional por parte de la gente joven, una valoración de la participación de la sociedad en la política nacional y la necesidad de fortalecer la democracia en la escuela.

Palabras clave: participación juvenil, política, educación ciudadana, democracia, escuela secundaria (Tesauro de Ciencias Sociales de la Unesco).

\section{Representations of 'the political' among secondary students in Santiago, Chile. Redefining the meaning of citizenship education}

- Abstract(descriptive): This article presents the results obtained from the study "Representations of 'the political' among secondary students and teachers of secondary schools in the metropolitan region: Guidelines for a new proposal for citizenship education”, undertaken in the city of Santiago, Chile. This study began with an initial quantitative exploratory phase to collect students' and teachers' perceptions about politics and associated concepts -democracy, power, participation. As

\footnotetext{
Este artículo de investigación científica y tecnológica (Otras ciencias Sociales, área interdisciplinaria) se basa en la investigación realizada por un grupo interdisciplinario de académicos y profesionales del Departamento de Estudios Pedagógicos (DEP) de la Facultad de Filosofía y Humanidades y el Departamento de Educación de la Facultad de Ciencias Sociales de la Universidad de Chile. Esta investigación fue apoyada y financiada por el Fondo Iniciativa Bicentenario (Oficio N² 291/acta n 11) de Revitalización de las Humanidades, las Artes, las Ciencias Sociales y las Ciencias de la Comunicación de la Universidad de Chile, y la llevamos a cabo desde el 28 de agosto de 2014 al 28 de enero de 2016. Nombre de la investigación: Representaciones de lo político en estudiantes y profesores/as de la educación secundaria en la Región Metropolitana. Criterios para una nueva propuesta de formación ciudadana.

** Magíster en Educación y Comunidad Educativa. Académica e investigadora. Orcid: 0000-0002-4727-4768. Correo electrónico: mravelo@uchile.cl

*** Magíster en Axiología y Filosofía Política. Máster en Ética y Democracia. Orcid: 0000-0002-8777-8864. Correo electrónico: yradovic@gmail.com
} 


\section{Marcia RaVElo-MEdina - Yubitza Radovic-SENDRA}

a second step, this study employed qualitative methodology to investigate the meanings attached by participants to the value and significance of politics and democracy at social and school levels. The results of the study show a withdrawal of young boys and girls from institutional politics, a high valuation of the participation of members of society in national politics and the need to strengthen democracy at schools.

Key words: youth participation, politics, citizenship education, democracy, secondary schools (Social Science Unesco Thesaurus).

\section{Representações políticas em estudantes secundários em Santiago do Chile. Resignificando o sentido da formação cidadã}

- Resumo (descritivo): este artigo apresenta, desde discursos dos e das estudantes, os resultados da pesquisa "Representações políticas nos estudantes e professores na educação secundária da Região Metropolitana de Santiago. Critérios para uma nova proposta de formação cidadã " realizada em Santiago do Chile. A pesquisa teve uma etapa exploratória quantitativa que coletou a percepção dos estudantes e professores sobre a política e conceitos associados, como democracia, poder e participação. A segunda etapa foi qualitativa, onde indagou os significados sobre o valor e o sentido da política e da democracia no nível escolar e social. Os resultados mostram um distanciamento entre os jovens da política institucional. Uma valorização da participação da sociedade na política nacional e a necessidade de fortalecer a democracia na escola.

Palavras-chave: participação juvenil, política, educação cidadã, democracia participativa, escola secundária (Thesaurus de Ciências Sociais da Unesco).

-1. Introducción. -2. Consideraciones teórico-metodológicas. -3. Resultados de la investigación desde el discurso estudiantil. -4. Conclusiones. -Lista de referencias.

\section{Introducción}

Nuestro interés en esta investigación se originó a partir de las manifestaciones estudiantiles de 2006 y 2011 en Chile; tales expresiones causaron gran impacto en la opinión pública y, desde entonces, ha habido una permanente fascinación por lo que parece ser una nueva forma de expresión y participación del colectivo de estudiantes de secundaria en la política nacional.

La premisa de la que partió el equipo de investigación fue que estas movilizaciones estudiantiles habían producido en el estudiantado de secundaria un cambio respecto de los sentidos y de las experiencias sobre lo político. A raíz de ello, nos formulamos la siguiente pregunta de investigación: ¿cómo entienden la política y lo político las nuevas generaciones juveniles secundarias a la luz de sus movimientos sociales?

Este interés investigativo tiene correspondencia con una serie de estudios sobre la movilización estudiantil chilena $\mathrm{y}$ con las transformaciones que desde la política pública se han venido presentando en la institucionalidad escolar del país, como la Ley de inclusión ${ }^{1}$. En tales estudios se ha mostrado interés por las movilizaciones secundarias y por otras expresiones ciudadanas como instancias de resistencia al modelo político y económico que opera actualmente en Chile como el denominador común de la sociedad chilena (Araujo \& Martuccelli, 2012).

El objetivo general que trazamos para la investigación fue comprender las representaciones con respecto a la política, la participación ciudadana y lo político, en los colectivos de estudiantes y de docentes, en diferentes liceos de Santiago, en tanto actores

$1 \quad$ Ley $\mathrm{N}^{\circ} 20.845$ (promulgada en 2015) que regula la admisión de estudiantes, elimina el financiamiento compartido - familia y escuela- y prohíbe el lucro en establecimientos educacionales que reciben aportes del Estado. 


\section{REPRESENTACIONES DE Lo POLÍtiCo EN ESTUDIANTES SECUNDARIOS EN SANTIAGO DE CHILE: RESIGNIFICANDO EL SENTIDO DE LA FORMACIÓN CIUDADANA}

concretos de este sistema educacional, que está determinado por un desplazamiento desde la formación para la vida democrática a una formación cuyo eje articulador es la utilidad para el mercado (Ruiz, 2010).

A nivel nacional y en algunos estudios institucionales recientes encontramos una apatía juvenil hacia la política y sus formas de representación, que se expresa en un $81 \%$ de jóvenes (de edades entre 15 a 19 años) que declara un desinterés en la política, mientras un $34 \%$ indica que conversa de política con familiares o amigos (Instituto Nacional de la Juventud, 2013). Nos pareció relevante profundizar sobre esos datos nacionales y sondear esa apatía, específicamente en la población juvenil escolar, dado nuestro interés por proponer algunos criterios para la formación ciudadana. Podemos adelantar sobre este punto que la fase exploratoria de nuestra investigación ratificó las estadísticas recién descritas y nos alentó a develar el trasfondo subjetivo de las mismas.

Si definimos la política como aquella conflictiva y permanente construcción del orden deseado (Lechner, 1990), podemos considerar que, en el contexto chileno actual, hay un nuevo orden deseado y gestado desde la organización de los individuos jóvenes en materias de la vida en común, que articula lo social y lo ético, así como una cierta búsqueda de comunidad. Es por ello que entre el Estado y el mercado podría estar surgiendo un tercer actor: la comunidad (Águila, 2013).

Lo anterior cobra relevancia cuando la movilización estudiantil no tiene un flujo directo y expedito hacia el Estado, puesto que sus consignas se han encontrado con la resistencia del sistema político, por más que aquellos que en el pasado reciente fueron sus líderes, hoy ocupen algún espacio en el poder político institucional (Ruiz \& Boccardo, 2015). Sin embargo, los nuevos movimientos sociales son agentes de politización que cuestionan los límites de lo político, es decir, de aquello que debe ser objeto de discusión pública (Programa de las Naciones Unidas para el Desarrollo, 2015).
En el presente artículo exponemos los resultados de la investigación, centrándonos en las representaciones estudiantiles, puesto que su comprensión nos parece de relevancia no solo por el impacto de sus demandas en lo social y las reformas de la política pública, sino también como desafío hacia una resignificación de la formación ciudadana.

\section{Consideraciones teórico-metodológicas}

\subsection{Algunas claves teóricas}

La investigación se inscribe en el campo de los estudios de juventud y política. Consideramos el concepto juventud (o juventudes) como una categoría socialmente construida, histórica y relacional (Aguilera, 2009, 2014; Reguillo, 2012). En este campo, en Chile se han producido investigaciones y reflexiones respecto al abordaje del concepto de juventud, tanto desde las categorías legales, las narrativas institucionales y la producción del cuerpo juvenil (Saa, 2014, 2016), como la incidencia de la escuela secundaria en la definición de proyectos de vida y trayectorias, al poner en tensión los objetivos de la misma con las expectativas y sueños de las personas jóvenes (Dávila \& Ghiardo, 2012; Molina, 2013).

Desde el ámbito político y macrosocial, en el estudio consideramos, en primer lugar, el concepto de juventud en relación con los conceptos de lo político y la política (Rancière, 2006); en segundo lugar, y respecto de esta, las mutaciones/emergencias contemporáneas desde la contingencia social y global (Beck, 1992; Bobbio, 1986; Giddens, 2011; Mouffe, 2007; Programa de las Naciones Unidas para el Desarrollo, 2015); y, en tercer lugar, la trama que se dibuja desde la subjetividad política y la conciencia histórica, en la relación sujeto e historia (Zemelman, 2010). Transversalmente a esto, observamos la discusión sobre el valor y el significado de la ciudadanía como deliberación e interés por lo público (Cortina, 1999, 2007).

Respecto a la participación política del estudiantado chileno se ha planteado una nueva 
forma de organización horizontal y participativa (Donoso, 2013; Muñoz, 2011). Sin embargo, algunas investigaciones dan cuenta de una despolitización de las personas jóvenes como consecuencia de la disociación entre memoria y ciudadanía (Reyes, Cruz \& Aguirre, 2016).

Ciertamente, la investigación se refiere al mundo escolar, pues nos interesamos en las representaciones de los sujetos estudiantes de educación media. Si como describen Dubet y Martuccelli (1998), durante la adolescencia se desarrolla un "sí mismo no escolar" (una subjetividad y vida colectiva independientes de la escuela), nos interesa rescatar el valor político que tiene la escuela en su socialización política, desde la perspectiva del estudiantado y, en concreto, sobre qué elementos la configuran como espacio de aprendizaje o desafección política.

\subsection{Claves metodológicas}

Epistemológicamente abordamos esta investigación desde la perspectiva fenomenológica que comprende y postula que tanto las acciones como las prácticas sociales constituyen una dialéctica que construye la realidad social determinada y determinante (Berger \& Luckman, 1999).

Desarrollamos la investigación a través de un diseño mixto. Por un lado y con carácter exploratorio, llevamos a cabo una fase cuantitativa a través de cuestionarios con escala Likert $^{2}$ aplicados a estudiantes y docentes. Esta fase la adelantamos seleccionando instituciones educativas de las distintas administraciones del sistema y modalidades de enseñanza, en los niveles de $3^{\circ}$ y $4^{\circ}$ medio - los dos últimos años de escolaridad-, en 7 de las 32 comunas de la Región Metropolitana. La muestra consistió en 519 estudiantes y 74 docentes de 10 colegios. Más adelante detallamos los aspectos metodológicos que conciernen a la muestra de estudiantes en tanto que constituyen el foco de este artículo.

$2 \quad$ El cuestionario consta de 45 preguntas referidas a temas tales como la participación, la representatividad, el funcionamiento de la democracia, el poder y la violencia.
Por otro lado, este carácter exploratorio tuvo como finalidad recoger algunas orientaciones sobre las preferencias y las prácticas del estudiantado de secundaria en el ámbito de la politización, sobre las que posteriormente profundizamos en la fase cualitativa a través de dos grupos de discusión y de tres entrevistas en profundidad aplicadas a una muestra no probabilística, intencionada y ajustada a los criterios como procedencia de distinta dependencia administrativa de los colegios, ${ }^{3}$ diversidad de género, diversidad de modalidad educativa. ${ }^{4}$

En síntesis, las estadísticas expresaron lo que el equipo de investigación consideraba algo previsible en el ámbito escolar. Un ejemplo de esta percepción se expone en las figuras 1 y 2 , (preguntas $\mathrm{N}^{\circ} 1 \mathrm{y} \mathrm{N}^{\circ} 20$ del cuestionario) que presentamos como ejemplo del cuestionario y en comparación con las percepciones de los profesores y profesoras.

3 En Chile la dependencia administrativa admite cuatro tipos según la clase de financiamiento: municipal (gratuita), particular subvencionada (co-pago de familias y municipio), particularprivada y administración delegada (a cargo de distintas fundaciones y corporaciones sin fines de lucro y en el ámbito de infraestructura a partir de 2005 por el Departamento de Infraestructura Escolar, DIE).

4 La modalidad de enseñanza admite en Chile tres tipos: humanístico-científica, técnica profesional y educación artística. 
Figura 1. Pregunta 1. ¿Qué opinión tiene usted sobre la política?



Figura 2. Pregunta 20 ¿Con qué frecuencia conversa con su familia o amistades sobre temas relacionados con la política?

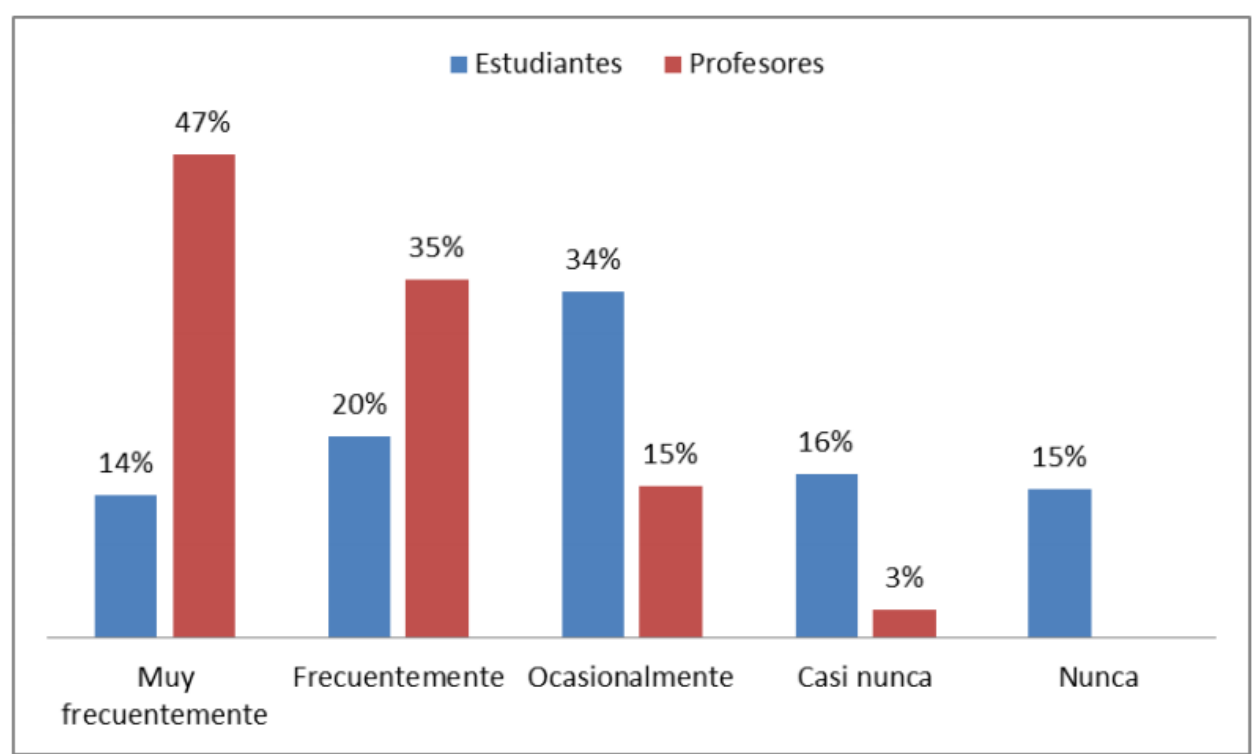

Esta apatía del estudiantado de secundaria por la actividad política cobra un notable giro en la fase de indagación de los significados construidos socialmente en relación con la política y lo político, puesto que se denota una valoración desde la resignificación de las tradicionales prácticas de participación en el país $\mathrm{y}$ una necesidad de reincorporar la formación ciudadana a la escuela desde la educación primaria y desde una visión de comunidad, en respuesta al modelo competitivo y de mercado que ha caracterizado a la educación chilena desde inicios de los años 1980.

Rev.latinoam.cienc.soc.niñez juv 16 (1): 389-402, 2018 http://revistalatinoamericanaumanizales.cinde.org.co doi: $10.11600 / 1692715 x .16124$

\section{Resultados de la investigación desde el discurso estudiantil}

Sobre la base de las entrevistas y grupos de discusión, identificamos los temas emergentes derivados del discurso oral y construimos dos unidades temáticas que corresponden a dos focos del discurso social; cada uno lo subdividimos en algunos temas o dimensiones.

Para el trabajo de análisis nos inspiramos en el enfoque por teorización anclada, poniendo énfasis en el proceso de teorización más que en la construcción de teoría (Mucchielli, 2001). Partimos de una lectura de los datos y 
procedimos a la categorización de los temas, a la que siguió una nueva lectura que basamos en una comparación reiterada entre teorización en construcción y realidad empírica que hace la relación entre categorías, para finalmente integrarlas en la producción de las unidades temáticas y subtemas.

Estas unidades temáticas son: 1) visión de la política, lo político y la participación ciudadana; 2) rol institucional, la escuela y el rol del sujeto docente en relación con la formación ciudadana.

\subsection{Visión de la política, lo político y la participación ciudadana}

\subsubsection{Distancias actuales y desafios} futuros en torno a la política.

Los individuos estudiantes valoran la política para la organización social, y lo hacen desde la satisfacción de las necesidades y la atención a sus derechos fundamentales. También la valoran desde la importancia que tiene para la vida del colectivo, como una acción para organizarse y proveerse de las condiciones materiales y simbólicas del desarrollo humano. No obstante, son enfáticos en distinguir el ámbito ideal de la política y el ámbito real en que se ejerce en el Chile actual:

La política para mí, dentro de una sociedad, es lo más importante porque sin ella no se puede concebir el mismo concepto de sociedad. Sin política no podríamos vivir en una sociedad en la que tengamos posibilidades de establecer ayuda mutua o distintas cosas; llevar la economía, llevar las relaciones públicas que tenemos como ciudadanos participantes de una sociedad. Ahi es cuando la política es el ente fundamental, la idea fundamental dentro de una sociedad (Grupo discusión 2, liceo municipal, varón).

Como la política la hacen las personas, es como labor de las personas, finalmente, participar de ella y cómo moverla, porque también tenemos que diferenciar "la política" de "lo político". La politica se puede entender muchas veces como el panorama nacional o lo que están haciendo en La Moneda o en el Parlamento, pero lo político es lo que nos influye a todos nosotros como ciudadanos, como seres humanos, y a nosotros nos corresponde participar de ella porque son los problemas que nos afectan a todos (Grupo discusión 1, colegio particular pagado, varón).

Existe una valoración de la política como actividad social que deriva de las movilizaciones sociales, pues estas han sacudido la pasividad de los estudiantes y las estudiantes que crecieron con la desafección política de los individuos adultos. Los sujetos estudiantes se autoperciben desencantados o descontentos con la representatividad de los profesionales de la política y con el sistema de participación que se ha institucionalizado en la democracia chilena, principalmente concentrada en el sufragio popular. Asimismo, exponen una alta valoración por la transformación política que, desde el discurso y desde incipientes prácticas de organización estudiantil, se gesta en los liceos de la Región Metropolitana. Hay que precisar que es distinguible esta visión en aquellos contextos escolares municipales.

Se le entrega el poder a unos cuantos, no decide la población entera. La democracia es la decisión del pueblo, si no me equivoco. El pueblo elige a ciertas personas y estas personas -los parlamentarios - deciden por el país. No es una democracia en términos estrictos, por decirlo así, y eso produce problemas (Grupo 1, colegio particular pagado, varón).

Las nuevas generaciones tienen menos miedo, o sea, se ve reflejado en los movimientos estudiantiles, el del 2000, el 2006, después el 2011, actualmente, aunque ha ido decayendo, pero igual, o sea, se da que los jóvenes —más que nada- se están atreviendo a decir: "somos una generación nueva y queremos cambios y queremos los cambios de verdad" (Entrevista, liceo municipal, varón).

Pese a este negativo diagnóstico sobre el actual estado de la política en ámbitos como la representatividad y la calidad de la 


\section{RePRESENTACIONES DE LO POLÍtiCO EN ESTUDIANTES SECUNDARIOS EN SANTIAGO DE CHILE: RESIGNIFICANDO EL SENTIDO DE LA FORMACIÓN CIUDADANA}

democracia, los estudiantes y las estudiantes advierten un cambio que se viene gestando y en el que se autoperciben como responsables de continuar desarrollándolo. Para ellos y ellas las movilizaciones estudiantiles y su impacto en la sociedad han remecido la "cultura ciudadana" de las personas chilenas hacia una mayor conciencia sobre la desigualdad social y la garantía del Estado en el derecho a la educación. Sin embargo, perciben a los sujetos adultos sin la suficiente convicción para rechazar el modelo social y económico heredado de la dictadura.

Debido a lo afectados que estuvieron [los adultos] esos años atrás, es un proceso que todavía está durando y está como en un círculo, avanzando lento, avanzamos $y$ retrocedemos, avanza y retrocede. Eso está llevando a que en este momento en Chile haya un problema de crisis, porque hay choque de generaciones; como la generación que tiene miedo a hablar y la generación que ahora está empezando a darse escuchar. Entonces, están en controversia (Grupo 1, liceo municipal, mujer).

Los jóvenes le enseñan a los adultos como ser mejor ciudadano que los adultos, nuestros papás, están acostumbrados... son hijos de la dictadura, nacieron en plena dictadura $y$, por ende, no tienen la conciencia de que ellos tienen derechos, de que ellos tienen que tener opinión (...) Por ejemplo, me pasa mucho que yo tengo continuas discusiones con mi mamá sobre que ella opina que - no sé- un ladrón de supermercado es más terrible que el dueño de una AFP.5 Ella encuentra que es lo más terrible del mundo ir y robar una galleta a un supermercado, pero a ella le da lo mismo que la AFP le cobre una millonada (Grupo 1, liceo municipal, varón).

Los sujetos estudiantes distinguen entre una política en crisis y una reorganización embrionaria de lo que sería una organización política nacional que atienda los problemas de las personas; se instalan en esa posición

5 Administradoras de Fondos de Pensiones; instituciones financieras privadas encargadas de administrar los fondos de pensiones de cuentas individuales de ahorro. histórica refundacional de lo político. Esa distinción ya nos permite indicar que ellos, a pesar de la supuesta apatía que se desprende en la fase cuantitativa, están politizando la discusión sobre el sistema actual, constituyendo una nueva subjetividad política que demanda cambios en los resabios políticos de la pasividad y de la lógica de los ciudadanos y ciudadanas espectadores. En suma, estarían asumiendo el rol de actores políticos que buscan proyectar transformaciones amplias a nivel social, no solo en el ámbito escolar, aunque sin todavía definir ni defender claramente qué implica aquello en términos de acciones concretas y frente a un sistema que se resiste con fuerza a la crítica.

Igual la consigna que más se repetía [en 2011] era el fin al lucro, que yo creo que es como transversal porque no abarca solamente a los estudiantes sino a los trabajadores, a todas las áreas de la sociedad. Eso igualfue supersignificativo, en el 2011 sobre todo, porque no fue una movilización solamente estudiantil sino igual generalizada (Grupo1, colegio particular pagado, mujer).

Yo lo veo de una manera superesperanzadora en ese sentido, yo siento que el hecho que exista gente moviéndose, haciendo colectivos, haciendo asambleas, que esté interesada en la política, que esté interesada en lograr un cambio, y a fomenta y promueve el mismo cambio. (...) Siento que el hecho de que se pongan en la mesa todas estas cartas como de cambio... se está discutiendo lo que se está haciendo politicamente en Chile y eso es ya superesperanzadory es bueno (Entrevista, colegio particular subvencionado, varón).

\subsubsection{Contextos escolares: espacios} abiertos o cerrados para participar.

Ahora bien, ¿cómo se relaciona la percepción de ese escenario macrosocial y nacional con el espacio escolar? En este ámbito es posible ir construyendo un abanico de experiencias de participación y de no participación, experiencias que dependen de las estructuras organizativas de los centros educativos, de la memoria reciente respecto 


\section{Marcia RaVElo-MEdina - Yubitza Radovic-SENDRA}

a las movilizaciones secundarias o de una concepción de la educación que no fomenta la participación desde etapas tempranas de la vida escolar. Respecto a esto último, el análisis devela que para los individuos estudiantes el sistema escolar representa una estructura social que reprime su opinión y tan solo deja un margen muy limitado de participación para que ellos tomen decisiones y accionen sobre sus contextos escolares; tales acciones se limitan al diseño de la celebración del día del estudiante, el aniversario del colegio o las votaciones de paralización por una marcha o paro nacional.

El colegio no te incentiva a hacer un centro de alumnos. En mi colegio el centro de alumnos se limitaba simplemente a hacer las alianzas [celebración aniversario], a hacer una tallarinata de vez en cuando, $y$ hace un par de años, con unos amigos que estábamos en segundo medio, se nos ocurrió hacer un centro de alumnos, pero participativo, o sea, de verdad para hacer un cambio (Grupo 1, colegio particular pagado, varón).

En síntesis, habría una misión paternalista, adultocéntrica y despolitizadora de la escuela chilena, independiente del tipo de dependencia administrativa y la modalidad de enseñanza de los centros educativos.

Yo, por ejemplo, doy el ejemplo de mi colegio de básica. Ahí no se habla de política porque simplemente los mismos directores están criados con la mentalidad de que el colegio es para enseñar y no para formar a una persona, o sea, enseñarles Matemáticas, Lenguaje, Física, Biología, pero no para crear una persona completa en el sentido político y social (Grupo 1, liceo municipal, mujer).

\subsubsection{Causas sociohistóricas de un} aprendizaje de desafección política.

Las personas estudiantes observan que en Chile existe una desafección política que califican como "distanciamiento respecto a la política" y que influiría no solo en la participación - por ejemplo en el sufragio-, sino en un distanciamiento de lo político. Las causas que generaría esta desafección política serían las siguientes:

\subsubsection{La dictadura.}

El estudiantado entiende la dictadura como un período que socavó la participación y generó una desesperanza política recluyendo a las personas en sus campos privados individuales (estudio, trabajo). Esta realidad habría marcado la generación de sus padres y madres como una generación alejada del campo de la política y encerrada en los espacios de la vida privada, sin participación ciudadana.

Son resabios de la dictadura: la poca participación ciudadana y que se vincula a que la mayoría de las cosas y actos políticos no son vinculantes. No hay actos vinculantes en la sociedad civil y con ello no hay participación ciudadana, y si la hay, no es resolutiva. Ese es el problema: debería haber un acto de encuentro resolutivo entre los distintos entes y grupos de la sociedad (Grupo 1, colegio particular pagado, varón).

Tal efecto dictatorial se ha mantenido en la actualidad y se refleja en la inacción y escaso involucramiento político de las personas; no se ha dado un aprendizaje ciudadano que corrija este efecto. Ello se requiere reparar desde lo que llaman la educación cívica, puesto que no se participará voluntariamente si las personas no lo tienen incorporado como algo propio y significativo. Cabe recordar que desde 2012 en Chile existe inscripción automática y voto voluntario.

Yo creo que el cambio parte en el Golpe. Yo creo que ahi está la razón fundamental porque la participación politica haya decaído sobre las personas. ¿Por qué? Porque antes del Golpe existian sindicatos, existian agrupaciones obreras que manifestaban de alguna forma la politica en las personas de clase baja que, por tanto, hacía que esta con la de centro y la derecha - que supone ser la clase alta- estén como trabajando en alguna forma juntos, como el que todas las visiones se interpongan y tengan entre ellas que llegar a un bien común (Entrevista, liceo municipal, varón).

El Gobierno pasado cometió un grave error en dejar las elecciones voluntarias en un país en que no hay educación 


\section{REPRESENTACIONES DE LO POLÍtiCO EN ESTUDIANTES SECUNDARIOS EN SANTIAGO DE CHILE: RESIGNIFICANDO EL SENTIDO DE LA FORMACIÓN CIUDADANA}

cívica, y no la ha tenido por años (Grupo

2 , liceo municipal, varón).

\subsubsection{Miedo y comodidad.}

El repliegue de la ciudadanía a los campos privados y la disminución de la participación en la vida pública se funda en el miedo, en la comodidad y en el conformismo. Las generaciones anteriores temen expresar opiniones diferentes por la desaprobación social que esto podría acarrear. Este miedo los conduce a mantener acalladas sus ideas con respecto a la sociedad y los mantiene alejados del campo de la política.

La gente dice que no quiere manifestar su opinión política por respeto, pero yo creo que es por miedo (Entrevista, colegio municipal, varón).

[Se trata de] conformismo. La gente está acostumbrada a que las cosas sean de tal manera al punto tal que dicen: "ya no lo podemos cambiar". Cree la gente que el sistema es de tal manera que va a seguir asi hasta que la gente muera porque asi siempre han sido las cosas, algo que también es hijo de la dictadura (Grupo 1, liceo municipal, mujer).

No es solo el conformismo sino satisfacción a la hora, satisfacciones propias, individuales; se corrompió el colectivismo, la solidaridad y cosas así y cayeron en el consumismo, en la satisfacción de comprarse algo y consumir cosas. Ahí está entonces el conformismo: yo trabajaba, me compraba esto y para qué quiero más (Grupo 1, colegio particular pagado, varón).

En contraste, los individuos jóvenes se ven a sí mismos como una generación con menos miedo a dar su opinión y dispuestos a participar en la transformación de aquellos aspectos de la vida social y política que profundizan las desigualdades y dificultan la posibilidad de desarrollo de una democracia participativa.

Yo creo que ahi se instaura el miedo. La manifestación más clara está como en que todavía tenemos una Constitución creada en dictadura, o sea, el miedo impuesto por la dictadura, a pesar de que no esté físicamente en la Constitución, está dentro de la gente, quizás en las personas más actuales no, pero en las generaciones anteriores que son la base del país actual, tienen como el miedo a decir (Entrevista, colegio municipal, varón).

Hay choque de generaciones; como la generación que tiene miedo a hablar y la generación que ahora está empezando a darse [sic] escuchar (Grupo 1, liceo municipal, varón).

\subsubsection{Individualismo capitalista.}

En el centro de la desafección política se levanta el profundo individualismo imperante en la sociedad actual, que tiende a profundizarse por la manera en que las generaciones jóvenes son educadas en y para el modelo neoliberal. El modelo remarcaría la competencia individual más que la participación y colaboración en proyectos comunes, ya sea en lo micro (comunidades vecinales, organización de estudiantes) o en proyectos sociales de carácter macro.

En el caso de mi generación, yo creo que es totalmente individualista [aunque] hay casos de personas que tienen desarrollado un sentido más de comunidad o de estar en pro de que todos salgan adelante, pero en general, está más enfocado en perseguir sus propios objetivos: por ejemplo, sacar un buen puntaje en la PSU [Prueba de Selección Universitaria]; entrar a una buena carrera; sacar una buena carrera $y$ después trabajar, tener familia, y el bien que persiguen es más propio que común porque están preocupados de ellos mismos porque la sociedad los ha llevado a ser más individualistas (Entrevista, liceo municipal, varón).

\subsubsection{Educaciónparalaparticipación:} una deuda pendiente.

Las personas estudiantes recalcan que la cercanía respecto a lo político en general y la participación dentro de la escuela depende muy estrechamente del establecimiento educativo. Las principales diferencias radican en el incentivo o en la contención de la participación 


\section{Marcia RaVElo-MEdina - Yubitza Radovic-SENDRA}

estudiantil, y en lo involucrado que el profesorado está en ese trabajo de formación.

Yo creo que desde chiquitito no se está incentivando en dar la opinión, como que se acostumbra el alumno a obedecer (...) porque dar su opinión es mirado, muchas veces, como falta de respeto - "niña insolente" o "escucha a tus mayores que saben más que tú"-. Yo creo que desde chiquitito se reprime $y$ en el momento - ya más grande- de dar su opinión prefieren no hacerlo (Entrevista, colegio particular subvencionado, mujer).

Esta fuerte diferencia entre un establecimiento y otro pondría de manifiesto que no existe una política nacional en lo que respecta a la formación política y ciudadana en los colegios, y el estudiantado vería reflejado aquello como un intento por "evitarse problemas" que, a la larga, produciría en los sujetos estudiantiles una desafección con el entorno y una desconexión con ámbitos relevantes de socialización, que merman el desarrollo de ciertos procesos cognitivos y de su identidad. En tal sentido, ellos valoran los espacios de diálogo que a partir del movimiento estudiantil se generaron entre diferentes establecimientos educativos, pues les han permitido ampliar su comprensión social, abordar diferentes temáticas e ir construyendo una postura propia, incidiendo en el entorno. Las tomas de los colegios las entienden como un medio legítimo que les han permitido ganar espacios internos de participación, inaugurando procesos de democratización institucional en instancias concretas como cambiar el número de evaluaciones por asignaturas, generar talleres con temáticas políticas y crear espacios de participación con directivos y otros miembros de la comunidad escolar.

En los emblemáticos ${ }^{6}$ generalmente hay mucha participación, pero también hay colegios donde no pasa nada o que no se deja que pase nada, y con esa cultura metida en los cabros [jóvenes] tampoco intentan buscarla (...) Aqui no se habla nada de eso, nada, nada, nada de los

$6 \quad$ Se refiere a liceos de dependencia municipal con altas puntuaciones en la evaluación estandarizada de acceso a la universidad (Prueba de Selección Universitaria). problemas que están pasando afuera; esto es totalmente aparte, toma un margen y ese margen yo encuentro que igual es malo porque ese mismo margen hace que los alumnos que estemos adentro nos marginemos de lo de afuera, que no se interesen en saber la realidad de otros colegios (Entrevista, colegio particular subvencionado, mujer).

\subsection{Rol institucional de la escuela en la formación ciudadana}

Los chicos y chicas estudiantes hacen una proyección sobre cómo la escuela debería formar en ciudadanía desde la enseñanza básica, y en tal planteamiento el rol de docentes es determinante para favorecer ambientes de participación a través de la estimulación y de la consideración de las percepciones y creencias de los niños y niñas.

[Es importante] que haya un fomento de la educación cívica desde una edad temprana. El problema nuevamente es la educación. Históricamente, Chile no ha tenido una educación cívica y un fomento estatal, gubernamental a la educación cívica y a la participación; el deber que tiene el ciudadano de relacionarse en su entorno, en su sociedad (Grupo 1, particular pagado, varón).

El profesorado promueve debates al interior de las salas de clase, ejercicio altamente valorado por el colectivo de estudiantes, aunque los profesores y profesoras lo perciben como una práctica a escondidas de la estructura organizacional educativa (autoridades), puesto que se le estimaría inadecuada en tanto la escuela no ha integrado la participación estudiantil como una experiencia formativa fundamental para la democracia.

\subsubsection{Cambio en la escuela:formación} para la democracia.

El estudiantado estima relevante el rol de la escuela en la formación ciudadana. Considera que hay poca democracia en la escuela, en las prácticas habituales y en la institución en general por parte del personal directivo.

Lo que pasa es que se escuchan las 


\section{REPRESENTACIONES DE Lo POLÍtiCo EN ESTUDIANTES SECUNDARIOS EN SANTIAGO DE CHILE: RESIGNIFICANDO EL SENTIDO DE LA FORMACIÓN CIUDADANA}

ideas, pero siempre son los directivos los que están tomando la decisión y los que van a ejercer el poder claramente; son Centro de Padres y Dirección. Entonces, claro, el Centro de Alumnos puede tener miles de iniciativas, miles de cambios, $y$ en cualquier momento cualquier persona que tenga un rango más alto se las va a trabar (Grupo 2, particular subvencionado, mujer).

Apreciamos que los estudiantes y las estudiantes de establecimientos (municipales) que participaron activamente de las movilizaciones estudiantiles de 2011 asumen con mayor optimismo la posibilidad de apertura de canales de participación escolar para mejorar la formación ciudadana; describen la importancia de poder formarse una opinión propia, cuestión que no se vincula exclusivamente con los contenidos de las disciplinas curriculares, sino con abrir espacios donde las ideas se discutan y se acuerden para generar los cambios respecto de las condiciones cotidianas de la vida escolar e interescolar.

Yo siento que en verdad el Centro de Estudiantes tiene que dirigir y promover la política, pero no todo tiene que recaer en el Centro de Estudiantes. El estudiantado tiene que proponer y ser un estudiantado proactivo y no se le puede poner todo el peso al Centro de Estudiantes (Entrevista, colegio particular subvencionado, varón).

Los grupos de estudiantes de los liceos donde ven disminuidas sus acciones de participación, destacan la necesidad de la formación ciudadana desde la educación básica (primaria), de manera que desde temprana edad dispongan de los espacios para ir construyendo participativamente una opinión e ir aprendiendo a posicionarse frente a otros y a escucharse mutuamente. Ellos y ellas tienen más dificultades para imaginarse tales espacios de participación activa que no solo consistan en expresar la propia opinión frente a los demás, sino también en generar acciones conjuntas. Invitados en las entrevistas a imaginar tal contexto, tuvieron dificultad para describirlo concretamente, puesto que es un ideal muy distante de su experiencia. Sin embargo, se presenta y alienta como un sueño para otra escuela.

El informarme, el incentivarme a estar informada; el darme la libertady sentirme bien en el momento de opinar. No sentir ese miedo cuando un profesor de repente te mira feo al opinar uno algo, o te hace callar. Entonces, esa es la herramienta que ellos me dan: la seguridad al yo dar mi opinión y que ellos me están respetando, aunque yo sea menor de edad, que respetan mi opinión como alguien (Entrevista, colegio particular subvencionado, mujer).

[Se trata de] dar instancias de debate en que se discutan noticias actuales porque ¿qué pasa? Si yo estoy debatiendo con una profesora y una compañera diferentes puntos de vista sobre una noticia y una compañera que no venoticias se dacuenta, va a decir: "yo no sé nada”, ¿cuál es mi opinión sobre esto? Entonces, encuentro yo, que si uno un poquito empieza los otros se van a incentivar y van a crear una mejor cultura de información (Entrevista, colegio particular subvencionado, mujer). Con suerte estoy pensando en un futuro en que se escuche la opinión, entonces llevarla a acciones; ya lo encuentro como un futuro tan lejano que no se me ocurre una idea. Lo encuentro como muy lejano (Entrevista, colegio particular subvencionado, mujer).

El estudiantado anhela espacios de discusión donde puedan desarrollar colectivamente el pensamiento crítico sobre la realidad que lo rodea. En este sentido, las personas jóvenes reclaman la participación estudiantil, no solo en función de su inserción a la política y a definirse como ciudadanos y ciudadanas, sino también en lo que concierne al desarrollo de la personalidad (individual y colectiva) y de la cultura.

\subsubsection{Proyectando una escuela para} la democracia.

Finalmente, ¿cómo puede la escuela ofrecer un espacio democrático para sus estudiantes desde el currículum y las actividades escolares? Los cambios sobre la materia se 


\section{Marcia RaVElo-MEdina - Yubitza Radovic-SENDRA}

han ido proyectando como correlato de las movilizaciones, y eso lo hemos expuesto en este análisis desde la perspectiva de los cambios en las significaciones políticas que producen las personas jóvenes. No obstante, el cambio en las prácticas educativas se realiza de manera lenta y requiere fortalecerse teniendo presente la desigualdad en la educación chilena. Una desigualdad que hay que enfrentar de manera de asumir una formación para la democracia, pues para los estudiantes y las estudiantes hay una relación directa entre una educación de calidad y los niveles de comprensión de la realidad social. Dicho de otro modo: no se puede ser crítico y participar de procesos sociales si no se ha experimentado una formación para saber hacerlo.

Tenemos que hacernos la pregunta de qué entendemos por democracia. Podría decirse que una interpretación es participar activa y directamente sobre las decisiones que se toman en un colegio, (...) con la realidad actual, estamos a años luz de lograrlo porque tiene que haber cierta transición en ese proceso. (...) ahí está la falla que tiene Chile o el porqué no ha surgido como un pensamiento crítico de la sociedad, porque la población no está, o sea, la base de un país como el nuestro debería ser la educación de calidad para que todos los individuos puedan tener una postura clara respecto a lo que vive el día a día (...) no es una educación de calidad (Grupo 1, liceo municipal, varón).

A partir del discurso sobre cómo se debiera entender la democracia y la política -y lo político-, los sujetos estudiantiles enfatizan la valoración de la diversidad para la vida democrática. Reconocemos un sueño y un desafío político que ven como tarea fundamental en la transformación de un sistema que ha sido insuficiente para la justicia social y para la educación democrática.

Al final todo lo que se está diciendo aquí lo tendremos que llevar a la práctica en algún momento porque estamos haciendo lo mismo que los políticos, los políticos hablan y hablan y al final nunca hacen nada. Nosotros no tenemos que hacer lo mismo. Decimos que tiene que haber más participación; tenemos que culturizarnos más con la política, pero tenemos que hacerlo y no quedarnos en solamente decirlo (...) Nosotros podemos cambiar el mundo si queremos. Utópico no es, si no, te estás limitando tú mismo (Grupo 1, liceo municipal, varón).

Esa responsabilidad para el futuro es tal vez el principal desafío que tiene también la escuela chilena para proyectar una democracia de calidad.

\section{Conclusiones}

El estudio nos ha mostrado cómo, a partir de la información obtenida en la exploración cuantitativa, se manifiesta una apatía juvenil respecto de la política, que no se condice con los resultados obtenidos tras la profundización cualitativa de la investigación. Esta muestra una valoración crítica de la política, por parte del colectivo de estudiantes, tanto para la vida en común como para su formación individual. $\mathrm{Su}$ discurso se ha direccionado hacia una crítica al sistema político actual en el país, enfatizando una crisis de representatividad de los políticos y del sistema democrático. A este último lo califican como deficiente en términos de participación genuina en la toma de decisiones sobre los cambios que se requieren y de los cuales sienten la necesidad de hacerse parte. Frente a esto, manifiestan también una insuficiencia del sistema escolar chileno en lo que se refiere a los ámbitos de su formación para la participación y la socialización política.

La investigación nos permite visibilizar con cierta nitidez la complejidad de las transformaciones que la sociedad chilena está experimentando y que se expresa en la escuela como espacio de concentración de los deseos, de las resistencias, de los anhelos y del sentir de las nuevas generaciones frente al modelo social y económico chileno. Es justamente desde esa réplica social que se expresa la denuncia y la utopía respecto a las posibles alternativas sobre la organización política del país. En este sentido, podemos reconocer en el discurso de estudiantes del estudiantado los cambios que la sociedad va alentando al ritmo de las consignas $\mathrm{y}$ de las marchas. 


\section{REPRESENTACIONES DE LO POLÍtico EN ESTUDIANTES SECUNDARIOS EN SANTIAGO DE CHILE: RESIGNIFICANDO EL SENTIDO DE LA FORMACIÓN CIUDADANA}

El discurso social juvenil nos permite construir algunos criterios pedagógicos de formación ciudadana que apuntan, a nuestro juicio, en dos direcciones: una, referida a lo pedagógico-didáctico, esto es, a desarrollar un enfoque para el aprendizaje mediante el diálogo y desde las primeras etapas de escolaridad, desalojando enfoques parametrales y verticalistas; y la otra dirección apunta hacia la convivencia escolar desde un enfoque para la formación ciudadana. Por un lado, que promueva la participación democrática en la discusión acerca de los temas que les interesen a los actores de la escuela y no solo en relación con temas rotulados de índole política, como el gobierno estudiantil. Por otro, como una experiencia cotidiana de discusión, de acuerdo y de acción sobre los aspectos públicos de la vida que impliquen lo curricular, lo evaluativo, la resolución de conflictos sociales y el diseño del proyecto educativo de cada escuela, resignificando en la convivencia escolar la formación ciudadana desde el hacer con otros para el bien de todas y todos.

Cabe, sin embargo, preguntarse si la insuficiencia del sistema escolar chileno en la socialización política de los niños, niñas y jóvenes puede resolverse solo desde criterios pedagógicos $\mathrm{y}$ de formación ciudadana, sin combatir los efectos de la dictadura en la configuración administrativa del sistema educativo donde la educación pública ha sido menoscabada en función de la privatización de los establecimientos educativos.

En este sentido, dada la estructura segregada de la educación chilena, resultaría interesante profundizar en futuras investigaciones sobre los mecanismos de participación en la vida escolar según las diferentes dependencias administrativas del sistema escolar chileno. Consideramos que una de las limitaciones de nuestro estudio ha sido no haber abordado cómo esta segregación influye en el proceso de formación política para la democracia.

\section{Lista de referencias}

Águila, E., \& Silva, E. (2013). Redéfinir le pouvoir et l'espace au sein de l' école. Une expérience d'autogestion communautaire au Chili. Revue Internsationale D'Éducation de Sevres, 64, 155-162. doi:10.4000/ries.3631

Aguilera, O. (2009). Estudios sobre juventud en Chile: coordenadas para un estado del arte. Última Década, 31, 109-127. doi:10.4067/ S0718-22362009000200007

Aguilera, O. (2014). Generaciones: movimientos juveniles, políticas de la identidad y disputas por la visibilidad en el Chile neoliberal. Buenos Aires: Clacso.

Araujo, K., \& Martuccelli, D. (2012). Desafios comunes: retrato de la sociedad chilena y sus individuos. Tomo I. Neoliberalismo, democratización y lazo social. Santiago de Chile: Lom.

Beck, U. (1992). Risk society: Towards a new modernity. Londres: Sage.

Berger, P., \& Luckmann, T. (1999). La construcción social de la realidad. Buenos Aires: Amorrortu.

Bobbio, N. (1986). El futuro de la democracia. México, D. F.: Fondo de Cultura Económica.

Cortina, A. (1999). Ciudadanos del mundo: hacia una teoría de la ciudadanía. Madrid: Alianza.

Cortina, A. (2007). Educar para una ciudadanía activa. Seminario de primavera. Madrid: Fundación Santillana. Recuperado de: http://www.fundacionsantillana.com

Dávila, O., \& Ghiardo, F. (2012). Transiciones a la vida adulta: generaciones y cambio social en Chile. Última Década, 20(35), pp. 69-83 doi:10.4067/S0718-22362012000200004

Donoso, S. (2013). Dynamics of change in Chile: Explaining the emergence of the 2006 Pingüino Movement. Journal of Latin American Studies, 45, 1-29. doi:10.1017/S002216X1200228

Dubet, F., \& Martuccelli, D. (1998). En la escuela: sociología de la experiencia escolar. Barcelona: Losada.

Giddens, A. (2011). Más allá de la derecha y la izquierda. Madrid: Cátedra.

Instituto Nacional de la Juventud. (2013). Séptima Encuesta Nacional de Juventud. Santiago de Chile: Autor. Recuperado de: http://www.injuv.gob.cl/portal/categoria/ publicaciones/encuestas/ 
Lechner, N. (1990). Los patios interiores de la democracia: subjetividad y política. México, D. F.: Fondo de Cultura Económica.

Molina, W. (2013). Juventudes escolarizadas, sentido y metáforas sobre el liceo público municipal en el Chile contemporáneo. Última Década, 21(38) pp. 37-65. doi:10.4067/S0718-22362013000100003

Mouffe, Ch. (2007). En torno a lo político. Buenos Aires: Fondo de Cultura Económica.

Mucchielli, A. (2001). Diccionario de métodos cualitativos en ciencias humanas $y$ sociales. Madrid: Síntesis.

Muñoz, V. (2011). Juventud y política en Chile: hacia un enfoque generacional. Última Década, 35, 113-141. doi:10.4067/S071822362011000200006

Programa de las Naciones Unidas para el Desarrollo. (2015). Desarrollo humano en Chile: los tiempos de la politización. Santiago de Chile: Autor.

Ranciére, J. (2006). Política, policía, democracia. Santiago de Chile: Lom.

Reguillo, R. (2012). Culturas juveniles: formas políticas del desencanto. Buenos Aires: Siglo XXI.

Reyes, M. J., Cruz, M. A., \& Aguirre, F. J. (2016). Los lugares de memoria y las nuevas generaciones: algunos efectos políticos de la transmisión de memorias del pasado reciente de Chile. Revista Española de Ciencia Política, 41, 93114. Recuperado de: doi:http://dx.doi. org/10.21308/recp.41.04

Ruiz, C. (2010). De la República al mercado: ideas educacionales y política en Chile. Santiago de Chile: Lom.

Ruiz, C., \& Boccardo, G. (2015). Los chilenos bajo el neoliberalismo: clases y conflicto social. Santiago de Chile: Nodo XXI, El Desconcierto.

Saa, M. (2014). Jóvenes delgadas, bellas y blancas: la producción del cuerpo juvenil en la publicidad. Última Década, 22(42). doi:10.4067/S0718-22362014000200004

Saa, M. (2016). Producir juventud en Chile: los jóvenes en los saberes, legislaciones e instituciones (1870-1930). Revista Austral de Ciencias Sociales, 30, 129-144.

Zemelman, H. (2010). Sujeto y subjetividad: la problemática de las alternativas como construcción posible. Poli. 27, 1-10. doi: $10.4000 /$ polis.943 